\title{
Взаимосвязь аккомодографических
}

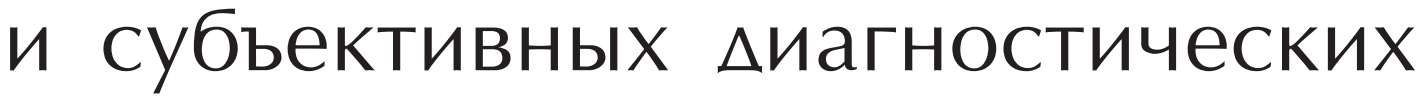
критериев различных нарушений \section{акКомодации}

\author{
М.В. Махова - врач-офтальмолог ${ }^{1}$ \\ В.В. Страхов - - -р меА. наук, профессор, заведуюший кафедрой офтальмологии ЯГМУ² \\ 1000 «Офтальмологическая клиника инновационных технологий», 150000, Ярославль, ул. Свободы, д. 91 \\ 2 ФГБОУ ВО ЯГМУ Минздрава России, 150000, Ярославль, ул. Революционная, д. 5
}

\begin{abstract}
Цель работы - изучение взаимосвязи объективных (аккомодографических) и субъективных критериев различных видов нарушений аккомодации. Материал и методы. Обследовано 62 пациента (124 глаза) в возрасте от 10 до 18 лет с миопической рефракцией. Всем пациентам, разделенным на 6 групп в зависимости от вида нарушения аккомодации, проведено исследование объективными методами - с помощью аккомодографии (аккомодограф Speеdy-I) с определением коэффициента аккомодационного ответа (КАO) и коэффициента микрофлюктуаций (КМФ) и МЕМ-ретиноскопии с определением аккомодационного ответа, а также субъективными методами - с помощью проксиметрии с определением амплитуды аккомодации и флиппера \pm 2 дптр с определением аккомодационной гибкости. Результаты. Выявлена достаточно тесная корреляционная связь между аккомодографическими и субъективными критериями оценки работоспособности цилиарной мышцы, в связи с чем для определения амплитуды аккомодации допустимо использовать как KAO, так и данные проксиметрии. Силу аккомодационного ответа можно определять с помощью КАО или МЕМ-ретиноскопии, а состояние аккомодации можно исследовать с помощью КМФ или аккомодационной гибкости. Заключение. Достоверная взаимосвязь между аккомодографическими коэффициентами и результатами субъективных методов исследования позволяет практикующим врачам амбулаторного звена использовать доступные субъективные методы для диагностики различных нарушений аккомодации, в соответствии с этим определять оптимальную оптическую коррекцию и выбирать адекватный метод лечения.
\end{abstract}

Ключевые слова: миопия, недостаточность аккомодации, перенапряжение аккомодации, субъективные и объективные методы исследования аккомодации, аккомодография, МЕМ-ретиноскопия, проксиметрия, аккомодационная гибкость

Для цитирования: Махова М.В., Страхов В.В. Взаимосвязь аккомодографических и субъективных диагностических критериев различных нарушений аккомодации. Российский офтальмологический журнал. 2019; 12 (3): 13-9. doi: 10.21516/2072-0076-2019-12-3-13-19

Конфликт интересов: отсутствует.

Прозрачность финансовой деятельности: никто из авторов не имеет финансовой заинтересованности в представленных материалах или методах. 


\title{
Interaction of accommodative and subjective diagnostic criteria of accommodation disorders
}

\author{
M.V. Makhova - ophthalmologist ${ }^{1}$ \\ V.V. Strakhov - Dr. Med. Sci., Professor, head of ophthalmology chair ${ }^{2}$ \\ ${ }^{1}$ Eye Clinic of Innovative Technologies, 91, Svobody St., Yaroslavl, 150000, Russia \\ 2 Yaroslavl State Medical University, 5, Revolutsionnaya St., Yaroslavl, 150000, Russia \\ yarmari@yandex.ru
}

Purpose: to study the relationship of accommodative (objective) and subjective criteria of different types of accommodation disorders. Material and methods. 62 patients (124 eyes) with myopic refraction, aged 10 to 18 , were divided into 6 groups according to accommodation disorders types. All patients were tested objectively on a Speedy-i accommodograph, which determined the coefficient of accommodation response (CAR) and the coefficient of microfluctuations (CMF) and underwent MEM retinoscopy to determine the accommodation response. In addition, subjective methods were used to determine the amplitude of accommodation (by proximetry) and accommodation flexibility (by \pm 2 D flipper). Results. A rather close correlation was revealed between the accommodative and subjective evaluation criteria of ciliary muscle performance. Therefore, both the CAR and proximetry data may be used to determine accommodation amplitude. The power of accommodation response may be determined by CAR and MEM retinoscopy, while the accommodation state may be tested by CMF or accommodation flexibility. Conclusion. A statistically significant correlation between accommodative coefficients and the results of subjective tests enable the practitioners of outpatient care to use the available subjective methods of accommodation disorder diagnosis and, accordingly, determine the best suited optical correction and choose adequate methods of treatment of accommodation disorders.

Keywords: myopia, accommodation disorders accommodation overstrain, subjective and objective methods of accommodation measurements, MEM retinoscopy, proximetry, accommodative flexibility

For citation: Makhova M.V., Strakhov V.V. Interaction of accommodative and subjective diagnostic criteria of accommodation disorders. Russian ophthalmological journal. 2019; 12 (3): 13-9 (In Russian).

doi: 10.21516/2072-0076-2019-12-3-13-19

Conflict of interests: there is no conflict of interests.

Financial disclosure: No author has a financial or property interest in any material or method mentioned.

Первые попытки классифицировать нарушения аккомодации предпринял А. Duane в 1915 г. [1]. В современной зарубежной литературе выделяют 4 типа нарушений аккомодации: аккомодационную недостаточность (accommodative insufficiency), аккомодационную неустойчивость (accommodative instability), чрезмерную аккомодацию (accommodative excess), невозможность аккомодации (accommodative infacility). В отечественной литературе мы встречаемся с несколько иным подходом к классификации нарушений аккомодации: спазм аккомодации, привычно-избыточное напряжение аккомодации (ПИНА), парез (паралич) аккомодации, слабость аккомодации, аккомодационная астенопия, пресбиопия [2].

Основные методы исследования аккомодации в нашей стране - это определение запасов относительной аккомодации (3ОА), за рубежом этот показатель называется relative accommodation reserves (RAR) [3], и объема абсолютной аккомодации (ОАА) [4]. Объективные методы исследования аккомодации основаны на регистрации изменений динамической рефракции в ответ на изменение аккомодационной задачи. Последнее может осуществляться с помощью перемещения объекта фиксации в пространстве (реальном или виртуальном) или с помощью линз различной силы и знака. При этом изменение динамической рефракции (аккомодационный ответ) сравнивается с аккомодационной задачей (в диоптриях) [5, 6]. Исследования последних лет, проведенные зарубежными учеными, показывают, что тонус цилиарной мышцы постоянно находится в колебании [7]. Эти колебания были названы аккомодационными микрофлюктуациями (АМФ). АМФ имеют определенную частоту и состоят из низко- и высокочастотного компонентов. Клиническое значение имеет высокочастотный компонент (частота 1,0 и 2,3 Гц), который отражает флюктуации формы хрусталика. Для исследования АМФ используется аккомодограф Speedy-I с программным обеспечением, который осуществляет частотный анализ АМФ методом Фурье. Компьютерная аккомодография позволяет детально диагностировать функциональное состояние аккомодации, ее работоспособность, 
оценивать ее динамические изменения, в том числе в процессе лечебных мероприятий [5, 7]. Визуальная оценка аккомодограмм позволяет формировать мнение о работоспособности и функциональных возможностях цилиарной мышцы.

ЦЕЛЫЮ работы является изучение взаимосвязи аккомодографических и субъективных критериев при различных видах нарушений аккомодации.

\section{МАТЕРИАЛ И МЕТОДЫ}

Обследовано 62 пациента (124 глаза) в возрасте от 10 до 18 лет с миопической рефракцией. В исследование включали только пациентов с симметричными аккомодограммами правого и левого глаза для исключения патологии вергенции [8]. Пациенты были разделены на 6 групп в зависимости от вида нарушения аккомодации: 1-я группа (24 глаза) с нормальным состоянием аккомодации с умеренной амплитудой; 2-я группа (18 глаз) - с нормальным состоянием аккомодации с высокой амплитудой; 3-я группа (18 глаз) - с недостаточностью аккомодации; 4-я группа (18 глаз) - с перенапряжением аккомодации с нормальной амплитудой; 5-я группа (18 глаз) - с перенапряжением аккомодации с низкой амплитудой; 6-я группа (28 глаз) - с перенапряжением аккомодации с высокой амплитудой.

Всем пациентам исследовали состояние аккомодации объективными методами - с помощью аккомодографии на аккомодографе Speedy-I с определением коэффициента аккомодационного ответа (KАО) и коэффициента микрофлюктуаций (КМФ) и с помощью МЕМ-ретиноскопии с определением аккомодационного ответа, а также субъективными методами - с помощью проксиметрии с определением ОАА и с помощью флиппера \pm 2 дптр с определением аккомодационной гибкости.

Измерение ОАА с помощью проксиметра Шаповалова проводилось следующим образом: лицевой упор направляющей линейки приставляли к наружному краю орбиты (узловая точка глаза), тестобъект - вращающееся кольцо Ландольта, соответствующее остроте зрения 0,7 для близи, - устанавливали напротив глаза на расстоянии около 2 см и медленно отодвигали от глаза до момента его четкого видения. Расстояние, на котором испытуемый различал детали тест-объекта, соответствовало ближайшей точке ясного зрения.

Для контроля положения дальнейшей точки ясного зрения мы использовали редуцирующую линзу +3 дптр. Редуцирующая линза перемещает дальнейшую точку ясного зрения из бесконечности на конечное расстояние перед глазом. Тест-объект отодвигают от глаза на 40-50 cм, а затем приближают к глазу до момента его четкого видения. ОАА - это разница в величинах ближайшей и дальнейшей точек ясного зрения.

Динамическая МЕМ-ретиноскопия проводилась в хорошо освещенной комнате, так как тусклое освещение может изменять аккомодационный ответ. Для проведения МЕМ-ретиноскопии использовали МЕМ-карты для ретиноскопа, которые крепятся с помощью магнита к головке ретиноскопа. Исследование проводилось с рабочего расстояния 40 см. Пока пациент читал слова на карте, начинали ретиноскопию по горизонтальной оси и оценивали силу положительных или отрицательных линз, необходимых для нейтрализации движения рефлекса ретиноскопа.

Измерение аккомодационной гибкости мы проводили таким образом: пациенту с полной коррекцией предъявляли текст на расстоянии 40 см, предварительно прикрыв ему один глаз окклюдером. Устанавливали флиппер \pm 2 дптр сначала с положительными линзами, при появлении четкого зрения переворачивали и устанавливали флиппер с отрицательными линзами. Тестирование проводилось в течение 60 с. Количество циклов указывает на гибкость аккомодации.

\section{РЕЗУЛЬТАТЫ}

До начала сравнительного анализа результатов исследования аккомодации объективным и субъективным способами нами по аккомодографическим критериям КАО и КМФ [4] на основании анализа 438 карт (876 глаз) были определены 6 состояний аккомодации, 3 из которых достаточно хорошо известны: нормальное состояние аккомодационной мышцы (рис. 1), перенапряжение аккомодации (рис. 2) и недостаточность аккомодации (рис. 3). Кроме того, с помощью аккомодографии оказалось возможным детализировать нормальное состояние аккомодации и перенапряжение аккомодации, что позволило выделить еще 3 группы: нормальное состояние аккомодации с высокой амплитудой (рис. 4) и перенапряжение аккомодации с нормальной и низкой амплитудой (рис. 5, 6). Коэффициент КАО характеризует амплитуду аккомодации, его нормальные значения находятся в пределах 0,75-0,85. Коэффициент КМФ также характеризует состояние аккомодации: КМФ ниже 62,5 Гц соответствует нормальному состоянию аккомодации, КМФ выше 62,5 характерен для перенапряжения аккомодации. На этом основании нами

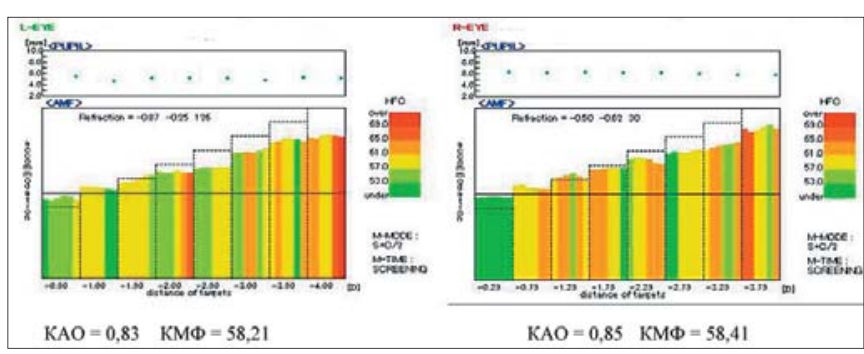

Рис. 1. Нормальное состояние аккомодации с умеренной амплитудой

Fig. 1. Normal accommodation with moderate amplitude 


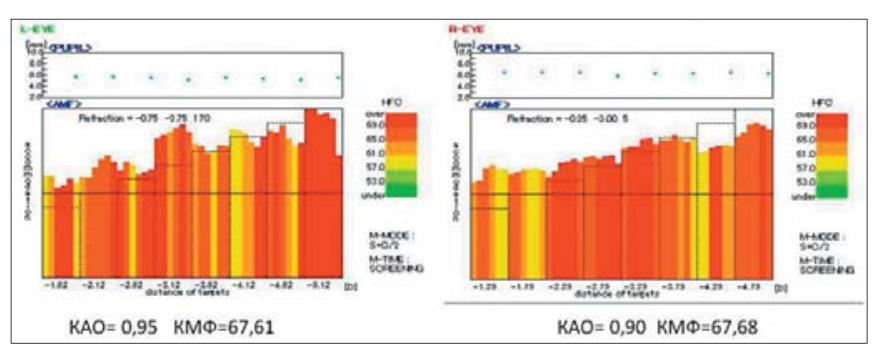

Рис. 2. Перенапряжение аккомодации с высокой амплитудой Fig. 2. The accommodation stress with high amplitude

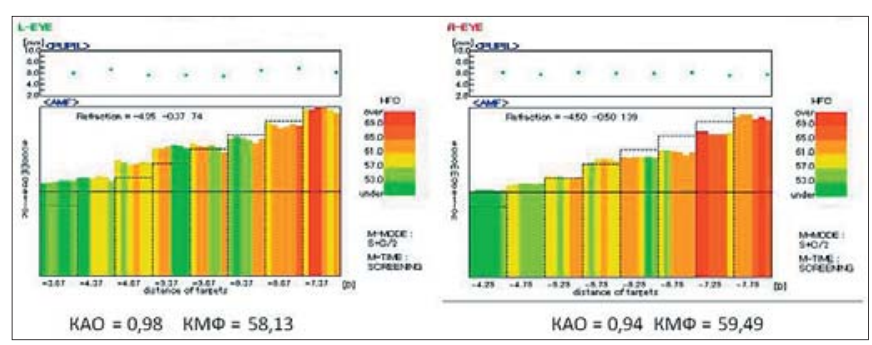

Рис. 4. Нормальное состояниеаккомодации свысокойамплитудой Fig. 4. Normal accommodation with high amplitude

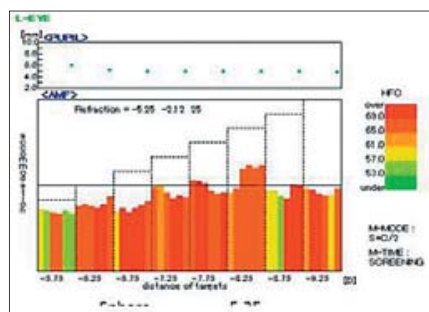

$\mathrm{KAO}=0,54 \quad \mathrm{KM} \Phi=66,90$

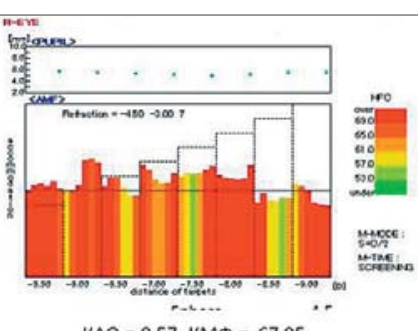

$\mathrm{KAO}=0,57 \mathrm{KM} \Phi=67,95$
Рис. 6. Перенапряжение аккомодации с низкой амплитудой Fig. 6. The accommodation overstress with low amplitude

впервые была предложена количественная характеристика различных состояний аккомодации (табл. 1).

Статистическая обработка результатов исследования (Statistica 7) выявила достаточно тесную связь между аккомодографическими и субъективными критериями оценки работоспособности цилиарной мышцы: между КАО и амплитудой аккомодации (ОАА) была установлена прямая корреляционная связь (R Spirman =0,53) (рис. 7), между КАО и аккомодационным ответом (МЕМ-ретиноскопия) обратная корреляционная связь высокой степени ( R Spirman = -0,95) (рис. 8), а между КМФ и аккомодационной гибкостью - умеренная обратная корреляционная связь (R Spirman $=-0,3)$ (рис. 9).

Пациентам из всех 6 групп для оценки работоспособности цилиарной мышцы, наряду с аккомодографией, было проведено исследование аккомодации субъективными методами. Для исключения влияния вергентного тонуса аккомодации исследования с использованием субъективных методов проводились монокулярно (табл. 2) [2].

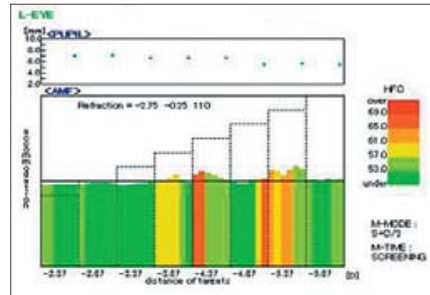

$\mathrm{KAO}=0,51 \quad \mathrm{KM} \Phi=54,29$

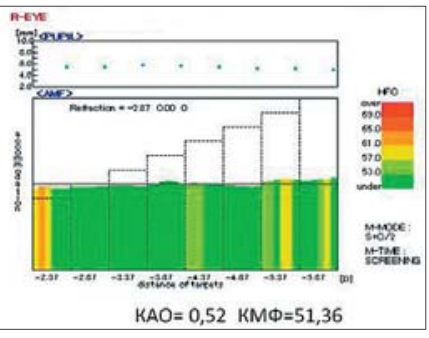

Рис. 3. Недостаточность аккомодации

Fig. 3. The accommodative insufficiency.

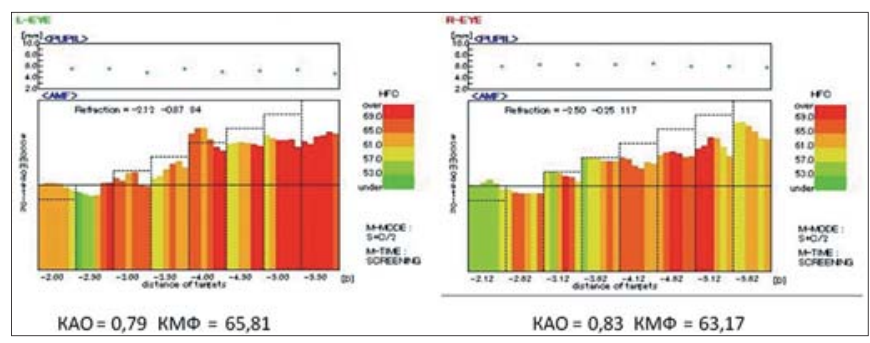

Рис. 5. Перенапряжение аккомодации с нормальной амплитудой.

Fig. 5. The accommodation overstress with normal amplitude

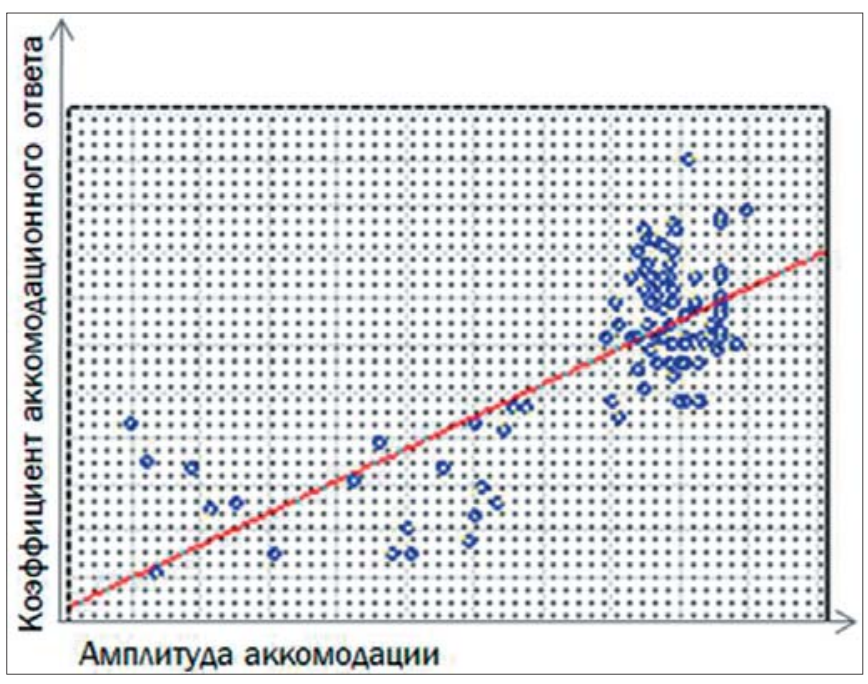

Рис. 7. Связь между коэффициентом аккомодационного ответа и амплитудой аккомодации ( $n=124), R$ Spirman $=0,53, p=0,001$. Fig. 7. Relationship between the ratio of accommodative response and the amplitude of accommodation $(n=124)$, R Spirman $=0.53$, $p=0.001$

Таким образом, опираясь на полученные коэффициенты корреляции, можно считать, что для оценки амплитуды аккомодации можно опираться как на КАО, так и данные проксиметрии.

Взаимозаменяемость объективных и субъективных методов исследования аккомодации означает, что силу аккомодационного ответа можно определить с помощью КАО или МЕМретиноскопии, а устойчивость аккомодационной мышцы можно оценить как с помощью КМФ, так и путем определения аккомодационной гибкости (табл. 2). 


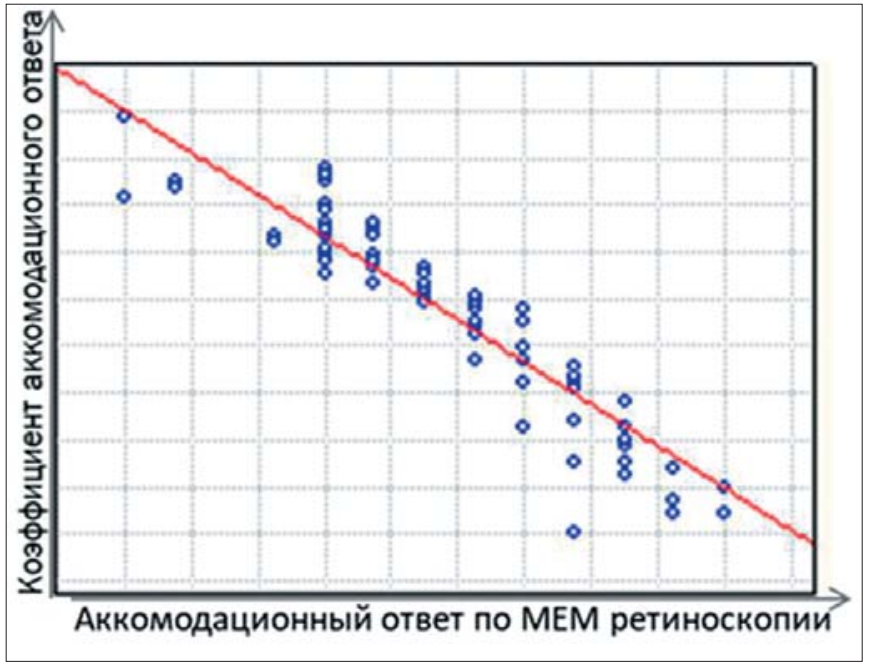

Рис. 8. Связь между коэффициентом аккомодационного ответа и величиной аккомодационного ответа по результатам МЕМретиноскопии $(\mathrm{n}=124), \mathrm{R}$ Spirman $=-0,95, \mathrm{p}=0,001$

Fig. 8. Relationship between the ratio of accommodative response and the magnitude of accommodative response according the results of MEM retinoscopy $(n=124)$, R Spirman $=-0.95, p=0.001$

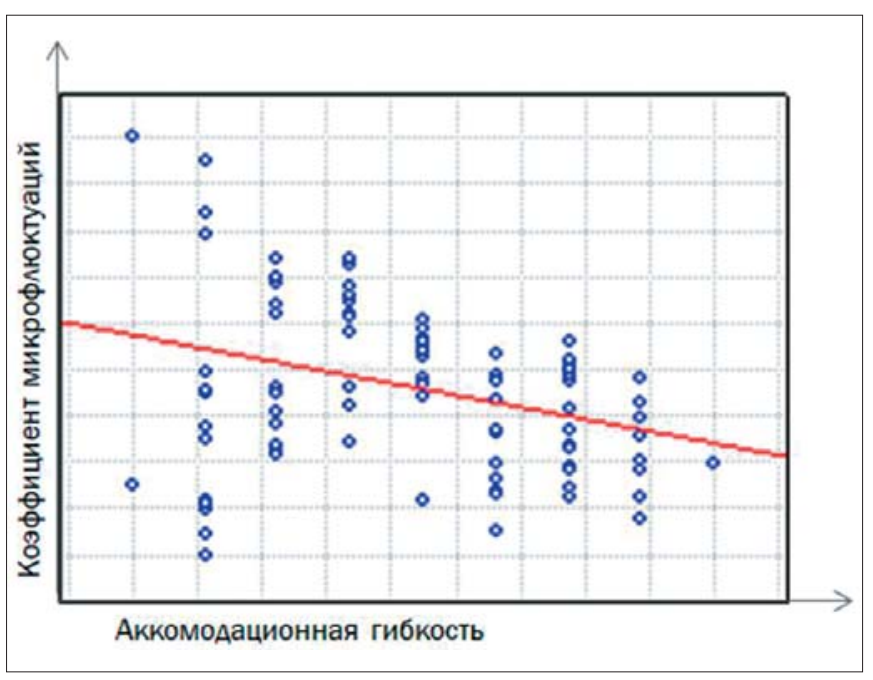

Рис. 9. Связь между коэффициентом аккомодативных микрофлюктуаций и аккомодационной гибкостью $(\mathrm{n}=124)$, R Spirman $=-0,3, p=0,001$

Fig. 9. Relationship between the coefficient of accommodative microfluctuations and accommodative facility $(n=124)$, R Spirman $=-0.3, p=0.001$

Таблица 1. Количественная характеристика различных состояний аккомодации в соответствии с аккомодографическими коэффициентами

Table 1. Quantitative characteristics of different accommodation states accordingly accommodation coefficients

\begin{tabular}{|c|c|c|c|c|c|c|}
\hline \multirow{2}{*}{$\begin{array}{l}\text { Показатели } \\
\text { Parameters } \\
\mathrm{n}=876\end{array}$} & \multicolumn{6}{|c|}{$\begin{array}{c}\text { Состояние аккомодации } \\
\text { State of accommodation }\end{array}$} \\
\hline & $\begin{array}{c}\text { нормальное } \\
\text { состояние } \\
\text { аккомодации } \\
\text { с умеренной } \\
\text { амплитудой } \\
\text { normal } \\
\text { accommodation } \\
\text { with moderate } \\
\text { amplitude, } \mathrm{n}=135\end{array}$ & $\begin{array}{c}\text { нормальное } \\
\text { состояние } \\
\text { аккомода- } \\
\text { ции с высокой } \\
\text { амплитудой } \\
\text { normal } \\
\text { accommodation } \\
\text { with high } \\
\text { amplitude, } \mathrm{n}=109\end{array}$ & $\begin{array}{c}\text { недостаточ- } \\
\text { ность аккомо- } \\
\text { дации } \\
\text { accommodative } \\
\text { insufficiency, } \\
\mathrm{n}=116\end{array}$ & $\begin{array}{c}\text { перенапряже- } \\
\text { ние аккомода- } \\
\text { ции с высокой } \\
\text { амплитудой } \\
\text { accommodation } \\
\text { overstress with } \\
\text { high amplitude, } \\
\text { n = } 120\end{array}$ & \begin{tabular}{|c|} 
перенапряже- \\
ние аккомода- \\
ции с нормаль- \\
ной амплитудой \\
accommodation \\
overstress \\
with normal \\
amplitude, $n=72$
\end{tabular} & $\begin{array}{c}\text { перена- } \\
\text { пряжение } \\
\text { аккомода- } \\
\text { ции с низкой } \\
\text { амплитудой } \\
\text { accommodation } \\
\text { overstress with } \\
\text { low amplitude, } \\
\text { n=58 }\end{array}$ \\
\hline $\begin{array}{l}\text { Рефрактометрия, дптр } \\
\text { Refractometry, D }\end{array}$ & $-3,37 \pm 2,09$ & $-3,168 \pm 1,980$ & $-3,75 \pm 2,38$ & $-3,39 \pm 2,29$ & $-3,54 \pm 1,88$ & $-4,24 \pm 2,82$ \\
\hline $\begin{array}{l}\text { Коэффициент } \\
\text { аккомодационного } \\
\text { ответа } \\
\text { Coefficient of accom- } \\
\text { modation response }\end{array}$ & $\begin{array}{c}0,75-0,85 \\
0,79 \pm 0,05\end{array}$ & $\begin{array}{c}>0,85 \\
0,92 \pm 0,08\end{array}$ & $\begin{array}{c}<0,75 \\
0,61 \pm 0,09\end{array}$ & $\begin{array}{c}>0,85 \\
0,95 \pm 0,08\end{array}$ & $\begin{array}{l}0,75-0,85 \\
0,8 \pm 0,03\end{array}$ & $\begin{array}{c}<0,75 \\
0,62 \pm 0,10\end{array}$ \\
\hline $\begin{array}{l}\text { Коэффициент } \\
\text { микрофлюктуаций, Гц } \\
\text { Coefficient of } \\
\text { microfluctuations, Hz }\end{array}$ & $\begin{array}{c}\leq 62,5 \\
59,06 \pm 2,11\end{array}$ & $\begin{array}{c}\leq 62,5 \\
59,34 \pm 2,02\end{array}$ & $\begin{array}{c}<62,0 \\
57,84 \pm 3,14\end{array}$ & $\begin{array}{c}>62,5 \\
65,79 \pm 3,53\end{array}$ & $\begin{array}{c}>62,5 \\
65,01 \pm 2,10\end{array}$ & $\begin{array}{c}62,5-65,5 \\
65,70 \pm 2,23\end{array}$ \\
\hline
\end{tabular}

Примечание. $\mathrm{n}$ - количество глаз.

Note. $\mathrm{n}$ - number of eyes.

На основании достоверной взаимосвязи между КМФ и аккомодационной гибкостью можно выделить 3 состояния перенапряжения аккомодации: умеренное (І степени), выраженное (II степени) и стойкое (III степени) (табл. 3).

Предлагаемая трактовка нарушений аккомодации дает возможность практикующим врачам определиться с оптической коррекцией и выбрать адекватный метод лечения нарушений аккомодации.
Как показывает наш опыт, для снятия перенапряжения аккомодации целесообразно использовать медикаментозное лечение - инстилляции ирифрина БК [9] либо применить комплексный подход: сочетание медикаментозного лечения и аккомодационнорелаксационных тренировок, а при недостаточности аккомодации рекомендуется использовать оптикорефлекторные тренировки аккомодации и домашние упражнения, такие как «метка на стекле». 
Таблица 2. Аккомодографические и субъективные критерии различных видов нарушений аккомодации Table 2. Objective and subjective accommodation criteria for different types of accommodation disorders

\begin{tabular}{|c|c|c|c|c|c|c|}
\hline \multirow{2}{*}{$\begin{array}{l}\text { Показатели } \\
\text { Parameters } \\
\mathrm{n}=124\end{array}$} & \multicolumn{6}{|c|}{$\begin{array}{c}\text { Состояние аккомодации } \\
\text { Accommodation state }\end{array}$} \\
\hline & $\begin{array}{c}\text { нормальное } \\
\text { состояние } \\
\text { аккомодации } \\
\text { с умеренной } \\
\text { амплитудой } \\
\text { normal } \\
\text { accommodation } \\
\text { with moderate } \\
\text { amplitude, } \mathrm{n}=24\end{array}$ & $\begin{array}{c}\text { нормальное } \\
\text { состояние } \\
\text { аккомода- } \\
\text { ции с высокой } \\
\text { амплитудой } \\
\text { normal } \\
\text { accommodation } \\
\text { with high } \\
\text { amplitude, } \mathrm{n}=18\end{array}$ & $\begin{array}{c}\text { недоста- } \\
\text { точность } \\
\text { аккомодации } \\
\text { the } \\
\text { accommodative } \\
\text { insufficiency, } \\
\mathrm{n}=18\end{array}$ & $\begin{array}{c}\text { перена- } \\
\text { пряжение } \\
\text { аккомодации } \\
\text { с высокой } \\
\text { амплитудой } \\
\text { accommodation } \\
\text { overstress with } \\
\text { high amplitude, } \\
\text { n=28 }\end{array}$ & $\begin{array}{c}\text { перена- } \\
\text { пряжение } \\
\text { аккомодации } \\
\text { с нормальной } \\
\text { амплитудой } \\
\text { accommodation } \\
\text { overstress } \\
\text { with normal } \\
\text { amplitude, } \mathrm{n}=18\end{array}$ & $\begin{array}{c}\text { перена- } \\
\text { пряжение } \\
\text { аккомода- } \\
\text { ции с низкой } \\
\text { амплитудой } \\
\text { accommodation } \\
\text { overstress with } \\
\text { low amplitude, } \\
\text { n=18 }\end{array}$ \\
\hline $\begin{array}{l}\text { Рефрактометрия, дптр } \\
\text { Refractometry, D }\end{array}$ & $-2,97 \pm 2,18$ & $-2,69 \pm 2,26$ & $-3,66 \pm 2,49$ & $-2,44 \pm 2,09$ & $-1,56 \pm 1,27$ & $-3,16 \pm 1,35$ \\
\hline $\begin{array}{l}\text { Коэффициент } \\
\text { аккомодационного } \\
\text { ответа (KAO) } \\
\text { Coefficient of } \\
\text { accommodation response } \\
\text { (CAR) }\end{array}$ & $0,82 \pm 0,04$ & $0,93 \pm 0,05$ & $0,62 \pm 0,09$ & $0,94 \pm 0,06$ & $0,82 \pm 0,04$ & $0,62 \pm 0,07$ \\
\hline $\begin{array}{l}\text { Коэффициент } \\
\text { микрофлюктуаций } \\
\text { (КМФ), Гц } \\
\text { Coefficient of } \\
\text { microfluctuations (CMF), } \\
\text { Hz }\end{array}$ & $59,38 \pm 2,03$ & $59,48 \pm 1,98$ & $58,76 \pm 2,47$ & $64,84 \pm 2,09$ & $66,14 \pm 3,44$ & $65,77 \pm 2,81$ \\
\hline $\begin{array}{l}\text { Аккомодационный } \\
\text { ответ (AO) по МЕМ- } \\
\text { ретиноскопии, дптр } \\
\text { Accommodative } \\
\text { response (AR) by MEM } \\
\text { retinoscopy, D }\end{array}$ & $0,50 \pm 0,10$ & $0,05 \pm 0,18$ & $1,34 \pm 0,29$ & $-0,42 \pm 0,40$ & $-0,56 \pm 0,10$ & $-0,95 \pm 0,18$ \\
\hline $\begin{array}{l}\text { Амплитуда аккомодации } \\
\text { (AА), дптр } \\
\text { Amplitude of } \\
\text { accommodation (AA), D }\end{array}$ & $10,82 \pm 0,48$ & $11,34 \pm 0,40$ & $6,13 \pm 1,82$ & $10,24 \pm 0,34$ & $10,07 \pm 0,62$ & $10,80 \pm 0,60$ \\
\hline $\begin{array}{l}\text { Гибкость аккомодации } \\
\text { (ГА), циклы } \\
\text { Accommodative facility } \\
\text { (AF), cycles }\end{array}$ & $9,80 \pm 1,34$ & $8,8 \pm 1,5$ & $5,35 \pm 0,60$ & $7,8 \pm 1,4$ & $6,50 \pm 1,51$ & $6,80 \pm 1,60$ \\
\hline
\end{tabular}

Примечание. Различия между КАО и АО, КАО и АА, КМФ и ГА статистически значимы, $\mathrm{p}=0,001 . \mathrm{n}-$ количество глаз. Note. Differences between CAR and AR, CAR and AA, CMF and AF are statistically significant, $\mathrm{p}=0.001$. $n-$ number of eyes.

Таблица 3. Степень перенапряжения аккомодационной мышцы в зависимости от величины коэффициента аккомодативных микрофлюктуаций и аккомодационной гибкости

Table 3. Degree of accommodation muscle overstress depending on the value of the coefficient of accommodative microfluctuations and accommodative facility

\begin{tabular}{|c|c|c|c|}
\hline $\begin{array}{l}\text { Показатели } \\
\text { Parameters } \\
\mathrm{n}=64\end{array}$ & $\begin{array}{c}\text { I степень, умеренное } \\
\text { перенапряжение } \\
\text { аккомодации } \\
\text { I degree, a moderate } \\
\text { accommodation overstress } \\
\text { n }=28\end{array}$ & $\begin{array}{c}\text { II степень, выраженное } \\
\text { перенапряжение } \\
\text { аккомодации } \\
\text { II degree, pronounced } \\
\text { accommodation overstress } \\
\text { n=18 }\end{array}$ & $\begin{array}{c}\text { III степень, стойкое } \\
\text { перенапряжение } \\
\text { аккомодации } \\
\text { III degree, persistent } \\
\text { accommodation overstress } \\
\mathrm{n}=18\end{array}$ \\
\hline $\begin{array}{l}\text { Коэффициент микрофлюктуаций (КМФ), Гц } \\
\text { Coefficient of microfluctuations (CMF), Hz }\end{array}$ & $\begin{array}{l}62,60-64,55 \\
63,51 \pm 0,55\end{array}$ & $\begin{array}{l}64,56-66,50 \\
65,39 \pm 0,61\end{array}$ & $\begin{array}{c}>66,50 \\
69,07 \pm 2,19\end{array}$ \\
\hline $\begin{array}{l}\text { Аккомодационная гибкость (АГ), циклы } \\
\text { Accommodative facility (AF), cycles }\end{array}$ & $\begin{array}{c}8,0-10,0 \\
8,47 \pm 0,94\end{array}$ & $\begin{array}{c}7,0-6,0 \\
6,90 \pm 0,66\end{array}$ & $\begin{array}{c}\leq 5,0 \\
5,33 \pm 0,70\end{array}$ \\
\hline
\end{tabular}

Примечание. Различия между КМФ и АГ статистически значимы, $\mathrm{p}=0,001 . \mathrm{n}-$ количество глаз.

Note. Differences between CMF and AF is statistically significant, $\mathrm{p}=0.001 \mathrm{n}-$ number of eyes.

\section{ВЫВОДЫ}

1. Достоверная связь между аккомодографическими коэффициентами и данными МЕМретиноскопии с результатами таких субъективных методов исследования аккомодации, как проксиметрия и определение аккомодационной гибкости позволяют практикующим врачам амбулаторного звена адекватно диагностировать различные 
нарушения аккомодации, используя доступные субъективные методы.

2. Правильная трактовка нарушений аккомодации дает возможность врачу подобрать оптимальную оптическую коррекцию и выбрать наиболее эффективный метод их коррекции.

\section{Лumepamypa/References}

1. Duane A. Anomalies of accommodation clinically considered. Trans. Am. Ophthalmol. Soc. 1915; 1: 386-400.

2. Проскурина О.В., Жукова О.В. Нарушения аккомодации. В кн.: Катаргина Л.А., ред. Аккомодация: Руководство для врачей. Москва: Апрель; 2012: 75-5.

Proskurina O.V., Zhukova O.V. Violations of accommodation. In: Katargina L.A., ed. Accommodation: Guidelines for doctors. Moscow: April; 2012: 75-5 (in Russian).

3. Scheiman M., Wick B. Clinical management of binocular vision. Philadelphia: Lippincott Williams \&Wilkins, 2008.752 (in Russian).

4. Аветисов Э.С., Шаповалов С.Л. Методика клинического комплексного исследования аккомодации. Методические рекомендации. Москва; 1976.

Avetisov E.S., Shapovalov S.L. Method of clinical complex study of accommodation. Methodical recommendations. Moscow; 1976 (in Russian).
5. Тарутта Е.П. Объективная аккомодометрия. В кн.: Катаргина Л.А., ред. Аккомодация: Руководство для врачей. Москва: Апрель; 2012: 50-4

Tarutta E.P. Objective accommodation. In: Katargina L.A., ed. Accommodation: Guide for doctors. Moscow: April; 2012: 50-4 (in Russian).

6. Проскурина О.B. Тонус аккомодации у детей. Рефракционная хирургия и офтальмология. 2004; 4 (2): 16-9.

Proskurina O.V. Tone of accommodation in children. Refractive surgery and ophthalmology. 2004; 4 (2): 16-9 (in Russian).

7. Gambra E.J. Accommodative lag and fluctuations when optical aberrations are manipulated. 2009; 6: 1-15. doi:10.1167/9.6.4

8. Милявская Т.И., Игнатьев С.А. Бинокулярное зрение и его нарушения. Москва: МИК; 2018.

Milyavskaya T.I., Ignatiev S.A. Binocular vision and its disorders. Moscow: MIC; 2018 (in Russian).

9. Махова М.В., Страхов В.В., Пиликова П.А. Индуцированная сферическая аберрация роговицы и напряжение аккомодации у детей с миопической рефракцией. Российский офтальмологический журнал. 2018;11 (2): 10-5. doi.org/10.21516/20720076-2018-11-2-10-15

Makhova M.V., Strakhov V.V., Pilikova P.A. Induced spherical aberration of the cornea and the stress accommodation in children with myopia. Russian ophthalmological journal. 2018; 11 (2): 10-5 (in Russian). doi.org/10.21516/2072-0076-2018-11-2-10-15

Поступила: 10.05.2019 Принята к печати: 27.06.2019 